\title{
Knowledge on uterine prolapse among married women of reproductive age in $\mathrm{Nepal}$
}

This article was published in the following Dove Press journal:

International Journal of Women's Health

14 August 2014

Number of times this article has been viewed

\author{
Binjwala Shrestha ${ }^{1,2}$ \\ Bhimsen Devkota ${ }^{3,4}$ \\ Badri Bahadur Khadka ${ }^{5}$ \\ Bishnu Choulagai ${ }^{1,2}$ \\ Durga Prasad Pahari' \\ Sharad Onta' \\ Max Petzold ${ }^{6}$ \\ Alexandra Krettek ${ }^{2,7}$ \\ 'Department of Community Medicine \\ and Public Health, Institute of \\ Medicine, Tribhuvan University, \\ Kathmandu, Nepal; ${ }^{2}$ Department \\ of Internal Medicine and Clinical \\ Nutrition, Institute of Medicine, \\ Sahlgrenska Academy at University of \\ Gothenburg, Sweden; ${ }^{3}$ Development \\ Resource Centre, Kathmandu, \\ Nepal; ${ }^{4}$ Institute of Education, \\ Tribhuvan University, Kathmandu, \\ Nepal; ${ }^{5}$ National Health Education \\ Information and Communication \\ Centre, Ministry of Health and \\ Population, Government of Nepal, \\ Kathmandu, Nepal; ${ }^{6}$ Akademistatistik \\ - Centre for Applied Biostatistics, \\ Occupational and Environmental \\ Medicine, University of Gothenburg, \\ Sweden; ${ }^{7}$ Nordic School of Public \\ Health NHV, Gothenburg, Sweden
}

Correspondence: Binjwala Shrestha Department of Community Medicine and Public Health, Institute of Medicine, Tribhuvan University, Maharajgunj, Kathmandu 44600, Nepal Email binjwalashrestha59@gmail.com
Background: Uterine prolapse (UP), which affects about 10\% of women of reproductive age in Nepal, is the most frequently reported cause of poor health in women of reproductive age and postmenopausal women. Currently, women's awareness of UP is unknown, and attempts to unravel the UP problem are inadequate. This study aims to assess UP knowledge among married reproductive women, and determine the association between UP knowledge and socioeconomic characteristics.

Methods: Our cross-sectional descriptive study investigated 25 districts representing all five administrative regions, three ecological zones, and urban and rural settings. We used structured questionnaires to interview 4,693 married women aged 15-49 years. We assessed UP knowledge by asking women whether they had ever heard about UP, followed by specific questions about symptoms and preventive measures. Descriptive statistics characterized the study population regarding socioeconomic status, assessed how many participants had ever heard about UP, and determined UP knowledge level among participants who had heard about the condition. Simple regression analysis identified a possible association between socioeconomic characteristics, ever heard about UP, and level of UP knowledge.

Results: Mean age of participants was 30 years (SD [standard deviation] 7.4), 67.5\% were educated, $48 \%$ belonged to the advantaged Brahmin and Chhetri groups, and $22.2 \%$ were Janajati from the hill and terai zones. Fifty-three percent had never heard about UP. Among women who had heard about UP, 37.5\% had satisfactory knowledge. Any knowledge about UP was associated with both urban and rural settings, age group, and education level. However, satisfactory knowledge about UP was associated with administrative region, ecological zones, caste/ethnic group, and age group of women.

Conclusion: Fifty-three percent of participants had never heard about UP, and UP knowledge level was satisfactory in 37.\% of those who had ever heard about UP. Any knowledge was associated with urban/rural setting, age group, and education level, whereas satisfactory knowledge was associated with geography, caste/ethnic group, and age group. UP-related health promotion programs should target women from all caste/ethnic groups, age groups, and education levels, including urban and rural communities.

Keyword: associated factors, knowledge, uterine prolapse, associated factors, Nepal

\section{Background}

Uterine prolapse (UP) is the most frequently reported cause of poor health among women of reproductive age and postmenopausal women. The severity of uterine dislocation into the vagina is graded on a scale of $0-3$ (or 4 ), where 0 indicates no prolapse, and 3 (or 4) indicates procidentia, or complete prolapse. ${ }^{1}$ In Nepal, more than 1 million women suffer from UP, and most belong to the reproductive age group. ${ }^{2}$ 
Studies in different districts of Nepal suggest that prevalence of UP is $17 \%-27 \% .^{3}$ The Government of Nepal has recognized that UP is associated with reproductive health and rights, sex, equity, and empowerment of women. However, UP is not included as a Millennium Development Goal (MDG) indicator, even though quality maternal health care and UP-related health promotion programs are entry points to improve women's health status. According to the 2011 Annual Report of the Department of Health Services, outpatient service users included 23,670 cases of UP in the Mountain, Hill, and Terai zones $(6.12 \%, 61.27 \%$, and $32.6 \%$, respectively). Additionally, UP occurs in all administrative regions of Nepal $(16.65 \%, 36.66 \%, 23.04 \%, 12.95 \%$, and $10.70 \%$, respectively. ${ }^{4}$

In Nepal, women engage in hard work, including heavy lifting, with little or no rest during pregnancy or the postpartum period. Such activity contributes to high rates of UP. ${ }^{3}$ UP has been unsatisfactorily addressed and is a sensitive topic among women, families, and communities. Most women hide UP problems due to embarrassment, leading to personal problems (eg, domestic violence). The media has been proactive in raising awareness of UP since 2007, using various approaches to disseminate messages that discuss UP prevention and treatment. ${ }^{5}$ Key initiatives include awareness programs by various national, international, and nongovernmental organizations that work to reduce the problem through outreach camps, health institutions, female community health volunteers, and mass media. ${ }^{2}$ Similarly, the Uterine Prolapse Alliance of the Safe Motherhood Network Federation identified 21 organizations that work with the UP issue in various parts of Nepal. Among them, 13 organizations have advocacy and awareness programs that focus on increasing women's awareness of early symptoms, possible risk factors, and preventive measures of UP, as well as issues regarding violence against women resulting from UP. ${ }^{6,7}$ In 2009, the Family Health Division of the Ministry of Health developed operational guidelines for UP management and partnered with the National Health Education, Information and Communication Center to communicate UP prevention programs. ${ }^{8}$ There is still a knowledge gap about UP among women of reproductive age. Therefore, the present study aimed to assess UP knowledge among married women of reproductive age, and determine the association between UP knowledge and socioeconomic characteristics. Findings of this study could be useful in the development of strategic health promotion programs for the prevention of UP that target the general population of women of reproductive age.

\section{Methods}

\section{Study design and setting}

We used a cross-sectional study design. The study was conducted in 25 of the 75 districts in Nepal, representing all five East to Far-west administrative regions and three ecological zones (ie, Terai, Hill, and Mountain) in both urban and rural settings (Figure 1).

\section{Study participants and data sources}

Our study participants were married women in the reproductive age group. We applied multistage random sampling to select sample districts, village development committees (VDCs) of the respective districts, and households. In stage one, we randomly selected 25 districts from a list of districts belonging to five different administrative regions (ie, Eastern, Central, Western, Mid-western, and Far-western). In stage two, we randomly selected four VDCs and either one municipality or a VDC containing a district headquarters in each district. Stage two groups included 125 VDCs and five municipalities from 25 study districts. In stage three, we randomly and systematically selected households from each VDC and municipality. In each VDC and municipality, we used a lottery method to select the first household and added every alternate house for interview until 41 households were included.

\section{Study size}

Considering an $18 \%$ prevalence of exposure to information, education, and communication materials in local language, 95\% confidence interval (CI), and 10\% allowable error, the required sample size was calculated to include 1,750 respondents. After considering a design effect of 2.5 , we decided to include 4,375 women.

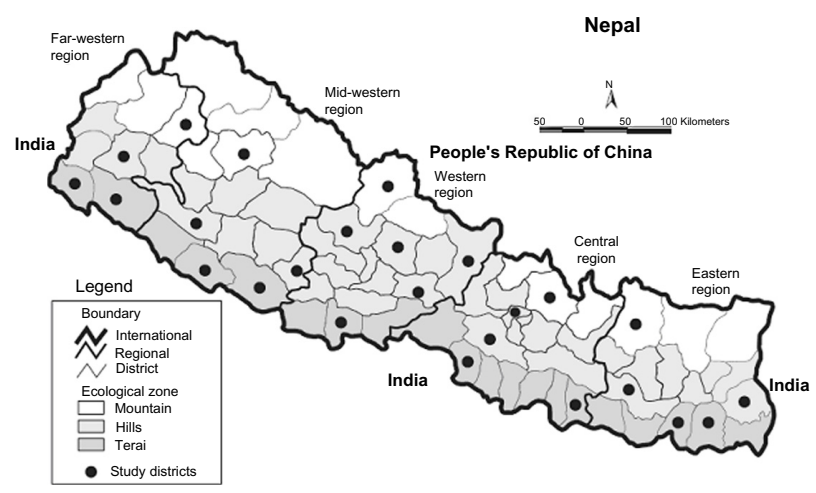

Figure I Map of Nepal indicating study districts showing the five administrative regions of Nepal, east to west, and three ecological zones, north to south.

Note: Dots indicate the location of 25 study districts in all geographical areas of Nepal. 


\section{Measurement}

We developed a structured questionnaire that comprised participants' sociodemographic and economic information, including address, age, marital status, main occupation, education status, and sufficiency of food production in a year. The questionnaire used the following questions to assess participants' knowledge of UP: 1) Have you ever heard about UP? 2) What are the major symptoms of UP? 3) What are the major preventive measures for UP? 4) What are the sources for accessing information about UP? The option for multiple responses for each question was developed with reference to a national UP campaign booklet, ${ }^{5}$ which contains facts and key messages about UP. A first draft of the questionnaire in English was later translated into the Nepali language. To ensure validity, the final Nepali version of the questionnaire was back translated into English. Next, we pretested the questionnaire during the enumerators' training session in a VDC in the Kathmandu district. The tool was subsequently finalized according to the findings of the pretest.

\section{Variables}

We divided the main variables of interest into three areas: 1) knowledge about UP (ie, ever heard about UP, multiple variables regarding symptoms and preventive measures of UP, proportion of the number of variables on knowledge assessment questions, and average or more knowledge about UP); 2) media exposure to access information about UP; and 3) socioeconomic characteristics (ie, geography, caste/ethnic group, ${ }^{10,11}$ age, education, source of income, and food sufficiency in a year). The variables used to assess the knowledge on UP for symptoms of UP were 1) difficulty lifting loads, 2) experiencing lower abdominal pain, 3 ) having a sagging uterus, 4) feeling pain during sexual activity, 5) difficulty controlling urine and to take preventive measures for UP, 6) not lifting heavy loads during the post-natal period, 7) eating nutritious foods during pregnancy and the post-natal period, 8) taking adequate rest during the post-natal period, 9) practicing family planning and birth spacing, 10) avoiding early pregnancy, 11) using institutional delivery, and 12) using safe abortion services.

\section{Data collection}

A structured interview was conducted with one participant from each household. Trained female enumerators holding a bachelor in public health degree conducted interviews using the structured questionnaire. We interviewed 41 participants in each study VDC and municipality. Two teams of supervisors oversaw the fieldwork. Data collection was conducted in March-July 2012.

\section{Data analysis}

Data were entered in EpiData Manager, version 1.4 (EpiData Association, Denmark), and statistical analyses were conducted with the Statistical Package for Social Sciences (SPSS), version 17.0 (SPSS Inc., Chicago, IL, USA). We used descriptive statistics to characterize the study population regarding socioeconomic status and to assess "ever heard about UP" among total participants. We also calculated the knowledge level about UP among participants who had ever heard about UP. Next, we described the proportion of variables in categories from 12 variables.

Participants who had ever heard about UP were further categorized according to the value of mean score from the sum of the 12 variables. We used below, mean, and equal or above mean of the sum of variables to assess the level of knowledge about symptoms and preventive measures of UP. Each variable was weighted equally. The result of equal and above to mean score was considered a satisfactory level of UP knowledge. This value was then used for further analyses to explore a possible association between socioeconomic characteristics of the study participants.

We performed bivariate and multivariate logistic regressions to determine the association between "ever heard about UP," satisfactory knowledge on UP, and background variables (eg, urban rural setting, developmental region, ecological zone, caste/ethnic group, age group, and education level). We checked collinearity among independent variables prior to inclusion in the regression. We identified no problem of collinearity among the independent variables that would bar them from the analysis. Our multiple logistic regression analysis included all independent variables that were significant at the $10 \%$ level in the univariate regression analyses. Statistical significance was set at $P<0.05$.

\section{Ethical considerations}

Issues regarding reproductive health are considered a private matter in Nepalese society, particularly among women. Because women feel uncomfortable speaking about reproductive health issues, they might be reluctant to respond to questions about UP symptoms and related issues. Therefore, we explained the importance of the study to each participant and conducted interviews only after obtaining informed consent. We also discussed and ensured respondents 
autonomy and confidentiality prior to each interview. This study was granted ethical approval by the Nepal Health Research Council (Reg no 56/2012).

\section{Results}

\section{Socioeconomic characteristics of the study participants}

This study included 4,693 married women in the reproductive age group. Nearly four of every five (78.6\%) respondents lived in rural communities; among these, 50.7\% lived in the hill zone. The mean age of participants was $30.0 \pm 7.4$ years. More than two-thirds (67.5\%) were educated $(26.5 \%$ at the primary level, $51.7 \%$ at the secondary level, and $19.2 \%$ at higher secondary level). Forty-eight percent of participants were from the advantaged group (Brahmin and Chhetri), and $22.2 \%$ were Janajati from the Hill and Terai zones. Regarding income source, $41.6 \%$ worked in agriculture, $23.4 \%$ worked in service, $17.6 \%$ were employed with wage labor, and $17.5 \%$ had foreign jobs (Table 1).

Table I Socioeconomic characteristics of the study participants $(\mathrm{N}=4,693)$

\begin{tabular}{|c|c|c|}
\hline Variables & $\mathbf{N}$ & $\%$ \\
\hline \multicolumn{3}{|l|}{ Developmental region } \\
\hline Eastern & 988 & 21.1 \\
\hline Central & 922 & 19.6 \\
\hline Western & $\mathrm{I}, 072$ & 22.8 \\
\hline Mid-western & 899 & 19.2 \\
\hline Far-western & 812 & 17.3 \\
\hline \multicolumn{3}{|l|}{ Ecological zone } \\
\hline Mountain & 969 & 20.6 \\
\hline Hill & 2,381 & 50.7 \\
\hline Terai & 1,343 & 28.7 \\
\hline \multicolumn{3}{|l|}{ Age group } \\
\hline$<20$ years & 203 & 4.3 \\
\hline $20-35$ years & 3,399 & 72.4 \\
\hline$>35$ years & $|, 09|$ & 23.2 \\
\hline \multicolumn{3}{|l|}{ Education level (grade) } \\
\hline Primary $(I-5)$ & 841 & 17.9 \\
\hline Secondary $(6-10)$ & 1,638 & 34.9 \\
\hline Higher secondary (II-I2) & 607 & 47.2 \\
\hline \multicolumn{3}{|l|}{ Caste/ethnic group } \\
\hline Dalit/socially suppressed from Hill and Terai & 493 & 10.5 \\
\hline Janajati/disadvantaged from Hill and Terai & 1,040 & 22.2 \\
\hline Caste group/non-Dalit from Terai & 313 & 6.7 \\
\hline Muslim/religious minority & 100 & 2.1 \\
\hline Newar, Thakali/relatively advantaged & 487 & 10.4 \\
\hline Brahmin, Chhetri/advantaged group & 2,251 & 48.0 \\
\hline \multicolumn{3}{|l|}{ Income source } \\
\hline Agriculture & I,504 & 41.6 \\
\hline Wage labor & 635 & 17.6 \\
\hline Foreign job & 630 & 17.4 \\
\hline Service & 843 & 23.4 \\
\hline
\end{tabular}

\section{Knowledge about UP}

More than half (52.9\%) of the participants responded that they had not heard about UP. Among 2,212 participants who had heard about UP, knowledge varied on the symptoms and preventive measures of UP. We used 12 variables of UP knowledge assessment questions (both symptoms and preventive measures of UP). Proportion of knowledge varied in four categories grouped according to the 12 variables. Among them, 26.8\% had highest knowledge (4-6 types of variables), and 3.8\% had lowest knowledge ( $>10$ types of variables). The proportion of perceived symptoms and preventive measures of UP was $21 \%-77 \%$ and $15 \%-81 \%$, respectively (Table 2 ). The mean score of 12 variables regarding symptoms and preventive measures of UP was 5.3 \pm 2.55 (95\% CI 5.2-5.4). Among the women who had ever heard about UP, $37.5 \%$ had a satisfactory level of knowledge (equal to and above average knowledge).

\section{Channel/source used by women, and level of knowledge in UP}

Women accessed information regarding UP from multiple sources/channels, including radio $(53.4 \%)$, television (48.4\%), female community health volunteers $(47.4 \%)$, friends/relatives $(45.0 \%)$, health workers $(36.5 \%)$, and newspapers $(24.4 \%)$. There were multiple answers regarding the channel/source used to access information about UP.

Table 3 shows the difference in percentage of women according to level of knowledge on UP and the type of channel/source used to access information about UP. The majority of participants (72.1\%) had satisfactory knowledge on UP and accessed information from health workers. Similarly, $67.8 \%$ of women had satisfactory knowledge and accessed information from female community health volunteers. Regarding other channel/source of information such as friends/relatives, radio, television, and newspaper, there was no difference in level of knowledge regarding UP.

\section{"Ever heard about UP" and socioeconomic background}

Table 4 shows differences in the association of "ever heard of UP" with rural/urban setting, caste/ethnic group, age, and education level. The odds that urban women ever heard of UP was 2.7 times higher compared with rural women. Similarly, compared with women from the advantaged castes (Brahmin and Chhetri), women from the socially 
Table 2 Distribution of ever heard and depth of knowledge about UP among study participants

\begin{tabular}{|c|c|c|}
\hline $\begin{array}{l}\text { Number of variables out of } 12 \text { types } \\
\text { of options }(N=4,693)\end{array}$ & $\mathbf{N}$ & $\%$ \\
\hline Never heard about UP & 2,481 & 52.9 \\
\hline Heard about UP & 2,212 & 47.1 \\
\hline \multicolumn{3}{|c|}{$\begin{array}{l}\text { Number of variables out of } 12 \text { types of options who had ever heard } \\
\text { about UP }(N=2,2 \mid 2)\end{array}$} \\
\hline $1-3$ & 460 & 20.9 \\
\hline $4-6$ & 1,266 & 56.9 \\
\hline $7-9$ & 314 & 14.2 \\
\hline$>10$ & 176 & 8 \\
\hline \multicolumn{3}{|c|}{ Perceived physical symptoms of UP (multiple responses) $(\mathrm{N}=2,2 \mid 2)$} \\
\hline Difficulty lifting loads & 1,572 & 76.9 \\
\hline Lower abdominal pain & $|, 40|$ & 68.5 \\
\hline Sagging uterus & 1,304 & 63.8 \\
\hline Pain during sexual activity & 626 & 30.6 \\
\hline Difficulty controlling urine & 433 & 21.2 \\
\hline \multicolumn{3}{|c|}{ Perceived preventive measures of UP (multiple responses) $(\mathrm{N}=2,2 \mathrm{I} 2)$} \\
\hline Not lifting heavy loads during post-natal period & $\mathrm{I}, 700$ & 81.6 \\
\hline $\begin{array}{l}\text { Eats nutritious foods during pregnancy and } \\
\text { post-natal period }\end{array}$ & $\mathrm{I}, 374$ & 65.9 \\
\hline Takes adequate rest during post-natal period & 1,021 & 49.07 \\
\hline Practices family planning and birth spacing & 833 & 40.0 \\
\hline Avoids early pregnancy & 675 & 32.4 \\
\hline Uses institutional delivery & 540 & 25.9 \\
\hline Uses safe abortion services & 328 & 15.7 \\
\hline
\end{tabular}

Abbreviation: UP, uterine prolapse.

suppressed (Dalit) and religious minority (Muslim) had 1.2 times and 1.6 times higher odds, respectively, of ever having heard of UP. However, we observed no significant associations between "ever heard of UP" and other caste/ethnic groups as compared with Brahmin and Chhetri women. Likewise, the odds of "ever heard of UP" among women who attended primary school and secondary school were 0.6 and 0.3 times lower compared with those who went to higher secondary school or above. The strengths of the associations were similar in both univariate and multivariate models.

Table 3 Channel/source used by women to access information about UP (multiple responses)

\begin{tabular}{lll}
\hline Channel/source & $\begin{array}{l}\text { Women } \\
\text { who heard } \\
\text { about UP, \% }\end{array}$ & $\begin{array}{l}\text { Women who had } \\
\text { satisfactory knowledge out } \\
\text { of channel/sources used, \% }\end{array}$ \\
\hline $\begin{array}{l}\text { Health workers } \\
\text { Female community }\end{array}$ & 36.5 & 72.1 \\
health volunteers & & 67.8 \\
Friends and relatives & 47.2 & 48.6 \\
Radio & 53.3 & 55.9 \\
Television & 47.2 & 46.1 \\
Newspaper & 22.3 & 17.9 \\
\hline
\end{tabular}

Abbreviation: UP, uterine prolapse.

\section{Knowledge about UP,}

\section{and socioeconomic background}

Table 5 shows the results of further analysis among women who had some knowledge of UP $(n=2,212)$ from the sum of the 12 variables. We found that neither place of residence (ie, urban or rural community) nor level of education was associated with knowledge of UP (data not shown). However, women residing in the Eastern, Central, Western, and Mid-western developmental regions had higher knowledge of UP than those in the Far-western region. Indeed, women from the Eastern region were 6.7 times more likely to have satisfactory knowledge compared with women from the Far-western region. Similarly, the odds of having satisfactory knowledge on UP were 5.6, 2.4, and 4.6 times higher in the Central, Western, and Mid-western regions compared with the Far-western region.

Furthermore knowledge about UP was significantly associated with ecological zone. The odds of satisfactory knowledge were 1.4 and 3.0 times higher in the Hill and Terai zones, respectively, than the Mountain zone. Compared with Brahmin or Chhetri women, satisfactory knowledge was 0.4, 0.6, and 0.9 times lower in Dalit and Newar/Thakali women, respectively. Compared with Brahmin and Chettri women, women of the non-Dalit caste group living in the Terai zone were 0.9 times more likely to have satisfactory knowledge.

Finally, women's age group was associated with UP knowledge. Compared with women aged $<20$ years, the odds of having UP knowledge were 0.4 and 0.3 times higher in women aged $20-35$ years and $>35$ years, respectively.

The strengths of associations in multivariate and univariate models were similar, except the odds that women of the age group 20-35 years would have satisfactory knowledge were 0.4 and 0.7 , and that of the age group $>35$ years were 0.3 and 0.5 , respectively.

\section{Discussion}

This is the first study to assess UP knowledge among women of reproductive age (15-49 years) in all five regions and three ecological zones of Nepal. Direct comparisons with other studies are difficult due to differences in questionnaires regarding UP-related knowledge items such as symptoms, perceived preventive measures, and treatment options. The local context might have caused variation in the understanding of the term uterine prolapse. To avoid this issue, we used the Nepali terms "Pathegharkhasne" or "Angkhasne." Similarly, the knowledge items in our study covered a wide range of topics directly related to messages designed for early symptoms and prevention of UP described in the 
Table 4 Association between "heard about UP" and socioeconomic factors $(\mathrm{N}=4,693)$

\begin{tabular}{|c|c|c|c|c|c|}
\hline Variables & $\begin{array}{l}\text { Ever heard } \\
\text { about UP (\%) }\end{array}$ & $\begin{array}{l}\text { Bivariate odds } \\
\text { ratio }(95 \% \mathrm{Cl})\end{array}$ & $P$-value & $\begin{array}{l}\text { Multivariate odds } \\
\text { ratio }(95 \% \mathrm{Cl})\end{array}$ & $P$-value \\
\hline \multicolumn{6}{|l|}{ Setting } \\
\hline Rural & 66 & I & & I & \\
\hline Urban & 22 & $2.5(2.2-3.0)$ & $<0.0001$ & $2.7(2.3-3.1)$ & $<0.0001$ \\
\hline \multicolumn{6}{|l|}{ Caste/ethnic group } \\
\hline Brahmin, Chhetri/advantaged & 59.2 & 1 & & I & \\
\hline Dalit/socially suppressed from Hill and Terai zones & 55.2 & $1.3(1.1-1.6)$ & 0.002 & $1.2(1.0-1.5)$ & 0.044 \\
\hline Janajati/disadvantaged from Hill and Terai zones & 57.2 & $0.9(0.8-1.0)$ & 0.420 & $0.9(0.7-1.0)$ & 0.309 \\
\hline Caste/non-Dalit from Terai zone & 58.8 & $0.99(0.77-1.25)$ & 0.911 & $0.99(0.77-1.27)$ & 0.919 \\
\hline Newar, Thakali/relatively advantaged & 46.4 & I.I (0.9-I.3) & 0.254 & $0.9(0.7-I . I)$ & 0.769 \\
\hline Muslim/religious minority & 15.4 & $1.9(1.2-2.8)$ & 0.002 & $1.6(1.0-2.5)$ & 0.018 \\
\hline \multicolumn{6}{|l|}{ Age group (years) } \\
\hline$>35$ & 61.9 & 1 & - & 1 & \\
\hline$<20$ & 29.1 & $0.7(0.6-0.8)$ & $<0.000 \mathrm{I}$ & $0.8(0.5-I . I)$ & 0.181 \\
\hline $20-35$ & 57.0 & $0.60(0.44-0.81)$ & 0.001 & $0.78(0.67-0.90)$ & 0.001 \\
\hline \multicolumn{6}{|l|}{ Education level (grade) } \\
\hline Higher secondary (I I-I2) & 83.8 & I & - & I & \\
\hline Primary $(I-5)$ & 41.6 & $0.5(0.5-0.6)$ & $<0.0001$ & $0.6(0.5-0.7)$ & $<0.0001$ \\
\hline Secondary $(6-10)$ & 15.8 & $0.3(0.3-0.4)$ & $<0.0001$ & $0.3(0.3-0.4)$ & $<0.0001$ \\
\hline
\end{tabular}

Abbreviations: $\mathrm{Cl}$, confidence interval; UP, uterine prolapse.

national campaign toolkit that was developed for Nepal in the national language. ${ }^{5}$

\section{UP is a recently disclosed issue and not integrated in the regular reproductive health program}

We found that more than $50 \%$ of the women in our study had never heard about UP, and only $37.5 \%$ of women who had ever heard about UP showed a satisfactory level of knowledge about UP. In other studies, $48.1 \%$ of women had proficient knowledge about pelvic organ prolapse in a community of New Haven, USA, ${ }^{12}$ and $29.6 \%$ of women in Alexandria, Egypt showed satisfactory knowledge about UP. ${ }^{13}$ A qualitative study in India shows that most women do not know the symptoms of UP. ${ }^{14}$ In Nepal, a national initiative to identify the prevalence and management of UP

Table 5 Association between knowledge of UP and various socioeconomic factors $(N=2,212)$

\begin{tabular}{|c|c|c|c|c|c|}
\hline Variables & $\begin{array}{l}\text { Satisfactory knowledge } \\
\text { of UP, \% }\end{array}$ & $\begin{array}{l}\text { Bivariate odds } \\
\text { ratio }(95 \% \mathrm{Cl})\end{array}$ & $P$-value & $\begin{array}{l}\text { Multivariate odds } \\
\text { ratio }(95 \% \mathrm{Cl})\end{array}$ & $P$-value \\
\hline \multicolumn{6}{|l|}{ Developmental region } \\
\hline Far-western & 17.6 & 1 & - & & \\
\hline Eastern & 57.0 & $6.2(4.5-8.5)$ & $<0.0001$ & $6.7(4.7-9.4)$ & $<0.0001$ \\
\hline Central & 45.9 & $3.9(2.8-5.4)$ & $<0.0001$ & $5.6(3.9-8.0)$ & $<0.000$ I \\
\hline Western & 28.9 & $1.9(1.3-2.6)$ & $<0.000$ I & $2.4(1.6-3.4)$ & $<0.000$ I \\
\hline Mid-western & 36.3 & $2.6(1.9-3.7)$ & $<0.0001$ & $4.6(3 . I-6.6)$ & $<0.000$ I \\
\hline \multicolumn{6}{|l|}{ Ecological zone } \\
\hline Mountain & 25.5 & 1 & - & - & \\
\hline Hill & 34.7 & $1.5(1.2-2.0)$ & 0.001 & $1.4(1.0-1.8)$ & 0.018 \\
\hline Terai & 50.7 & $3.0(2.2-3.9)$ & $<0.0001$ & $2.9(2.0-4.1)$ & $<0.000$ I \\
\hline \multicolumn{6}{|l|}{ Caste/ethnic group } \\
\hline Brahmin, Chhetri/advantaged & 38.2 & I & - & - & \\
\hline Dalit/socially suppressed from Hill and Terai & 20.9 & $0.4(0.3-0.6)$ & $<0.0001$ & $0.4(0.2-0.5)$ & $<0.000$ I \\
\hline Janajati/disadvantaged from Hill and Terai & 41.0 & I.I (0.9-I.4) & 0.306 & $0.6(0.4-0.7)$ & 0.000 \\
\hline Caste/non-Dalit from Terai & 52.0 & $1.7(1.2-2.5)$ & 0.003 & $0.9(0.6-1.4)$ & 0.886 \\
\hline Muslim/religious minority & 15.4 & $0.2(0.0-1.3)$ & 0.113 & $0.1(0.0-0.5)$ & 0.009 \\
\hline Newar, Thakali/relatively advantaged & 34.1 & $0.8(0.6-1.1)$ & 0.250 & $0.6(0.5-0.9)$ & 0.023 \\
\hline \multicolumn{6}{|l|}{ Age group (years) } \\
\hline$<20$ & 31.6 & 1 & & & \\
\hline $20-35$ & 38.8 & $0.7(0.6-0.8)$ & 0.001 & $0.4(0.2-0.8)$ & 0.019 \\
\hline$>35$ & 53.3 & $0.5(0.4-0.8)$ & 0.000 & $0.3(0.1-0.6)$ & 0.001 \\
\hline
\end{tabular}

Note: Satisfactory level of knowledge about UP = equal and above equal mean of the variables.

Abbreviations: $\mathrm{Cl}$, confidence interval; UP, uterine prolapse. 
began in 2005. However, UP-related health programs are still not integrated within the national reproductive health program on a regular basis. ${ }^{8}$

Various nongovernmental organizations are working on a project basis to reduce UP in Nepal, supported by international donor agencies. The Government of Nepal identified UP as an important issue of reproductive health communication. ${ }^{15}$ However, both the current national communication strategy for maternal, newborn, and child health ${ }^{16}$ and a national document for a minimum package of maternal and neonatal health care ${ }^{17}$ lack a specific strategy of counseling for UP prevention. Therefore, the task of increasing awareness of UP, which carries both cultural issues and social stigmatization, is challenging. In Nepal, social norms prevent women from discussing reproductive health problems with other family members or elders, ${ }^{18}$ mostly due to embarrassment, stigma, and harassment by family and/or spouse. ${ }^{19}$

\section{Differences in "ever heard about UP" and satisfactory level of knowledge on UP}

We found a $16 \%$ difference between the proportion of women who had heard about UP and those who exhibited a satisfactory level of UP knowledge. This could be due to low sociocultural status and unsatisfactory or nonexistent strategic health communication programs. Exposure to media to access UP-related health information is another issue for discussion. In our study, participants accessed health information from radio, TV, female community health volunteers, and friends or relatives. In Pakistan, 59\% of all women are exposed to all three types of media: $37 \%$ obtain information via radio, $57 \%$ via television, and $14 \%$ via printed matter. ${ }^{20}$ When the mass media cannot openly discuss reproduction issues, and health workers and community volunteers lack counseling skills, lack of knowledge on how to prevent UP will always exist.

\section{Knowledge on UP and its associated factors}

In our study, "ever heard about UP" was associated with women's education level, urban and rural setting, and age group. On the other hand, a satisfactory level of knowledge on UP was associated with geography (both administrative region and ecological zone). This could be due to a difference in human development index between the Far-western region $(0.39)$ and the Eastern region $(0.48)^{21}$ or that UPrelated health-promotion programs have not yet reached the Far-western region. The proportion of television viewers is highest (68\%) in the Eastern Terai zone, and the Central and
Eastern zones have more newspaper readers (54\%). ${ }^{4}$ These differences in health promotion programs could explain the variation in satisfactory level of UP knowledge in the entire country.

The 2011 Nepal Demography and Health Survey (NDHS 2011) demonstrated that class, caste/ethnic group, and education is significantly associated with health knowledge and reproductive health care-seeking practices. ${ }^{10}$ A study from India has shown that age, education, occupation, place of residence, and economic status are major factors affecting awareness of reproductive health issues. ${ }^{22}$ The present study showed that age group was associated with UP knowledge. School curriculum and the training manual for female community health volunteers do not provide adequate information regarding risk factors for UP and fail to develop knowledge regarding UP prevention. ${ }^{23}$ Inadequate school education for sexual and reproductive health and lack of focus on UP prevention in female community health programs might explain the current variation in satisfactory UP knowledge among adolescent females and other age groups.

Education is associated importantly with UP knowledge, and low education level presents a strong barrier to the use of antenatal and skilled birth attendants' services and HIV/ AIDS awareness. ${ }^{21}$ Interestingly, we found that education and urban/rural residence did not associate with satisfactory knowledge about UP, possibly due to social norms and personal perception of UP. Even educated women from urban settings do not disclose UP, probably due to tradition and feelings of shame in their given social context.

According to NDHS 2011, women access health information from various media, including print (12.6\%), television (47.4\%), and radio (44.2\%). Only $7.4 \%$ of the women studied in that survey had access to all three media. ${ }^{4}$ Moreover, the preferred sources of information for UP-related messages in our study were health workers, friends/relatives, and female community health workers. This data shows differences in media preference and availability.

The findings presented here can be generalized among women of reproductive age in low-income countries. Future research should focus on exploring attitude, behavior on UP, and which media women prefer for accessing information about UP.

\section{Conclusion}

Fifty-three percent of the women in our study had never heard about UP, and among the women who had ever heard about UP, only $37 \%$ had a satisfactory level of knowledge. 
"Ever heard about UP" was associated with urban and rural settings, age group, and education level. Satisfactory level of UP knowledge was associated with geography (ie, developmental region and ecological zone), caste/ethnic group, and age group. Therefore, we recommend that UP-related health promotion programs should target women in all caste/ ethnic groups, age groups, and education status nationwide, including both urban and rural communities. Nepal should engage in strategic media planning to address primary prevention of UP.

\section{Acknowledgments}

We would like to thank the Government of Nepal as well as the National Health Education Information Communication Centre for providing datasets of formative research in 2012. We are grateful for the hard work of the team of the Development Research Centre during data collection and quality assurance of the study. University of Gothenburg, Sweden, provided travel grants through a "Global University" grant (A11 0524/09). The authors thank scientific editor Karen Williams (Kwills Editing Services, Weymouth, MA, USA) for providing professional English-language editing of this article.

\section{Authors' contributions}

All authors contributed toward data analysis, drafting and revising the paper and agree to be accountable for all aspects of the work.

\section{Disclosure}

The authors declare that they have no competing interests.

\section{References}

1. Kumari S, Walia I, Singh A. Self-reported uterine prolapse in a resettlement colony of North India. J Midwifery Womens Health. 2000;45:343-350.

2. Bodner-Adler B, Shrivastava C, Bodner K. Risk factors for uterine prolapse in Nepal. J Int Urogynecol J Pelvic Floor Dysfunct. 2007;18(11):1343-1346.

3. Gurung G, Rana A, Amatya A, et al. Pelvic organ prolapse in rural Nepalese women of reproductive age groups: what makes it so common? Nepal J Obstet Gynaecol. 2007;2:35-41.

4. Ministry of Health and Population (MoHP) [Nepal]. Annual Report of Health services 2010/2011. Government of Nepal, Kathmandu: MoHP; 2011.

5. UNFPA, Government of Nepal. Booklet on uterine prolapse. Sancharika Samuha; 2007.

6. Safe motherhood network federation Nepal. Proceedings on formation of uterine prolapse alliance workshop; April 6, 2007; Kathmandu, Nepal. Available from: http://www.advocacynet.org/modules/fck/ upload/file/upa/Proceedings $\% 20$ on $\% 20$ Formation $\% 20$ of $\% 20$ Uterine $\%$ 20Prolapse\%20Alliance\%20Workshop\%206\%20April\%202007.pdf. Accessed August 15, 2013.

7. Safe Motherhood Network Federation Nepal. Report of Second National Safe Motherhood Conference; October 6, 2006; Kathmandu, Nepal. Available from: http://www.docstoc.com/docs/75048386/2nd-NationalSafe-Motherhood-Conference. Accessed August 12, 2013.
8. Ministry of Health and Population, Nepal. Health Sector ProgrammeImplementation Plan II (NHSP IP II) 2010-2015. Government of Nepal; 2010. Available from: http://www.mohp.gov.np/english/files/ new_publications/NHSP-IP\%20II\%20.pdf. Accessed August 26, 2013.

9. National Health Education, Information Communication Centre (NHIECC), Effectiveness of District Specific IEC Activities on Health and Primary Health Care Services. Kathmandu: Government of Nepal NHEICC; 2006.

10. Bennett L. Gender Caste and Ethnic exclusion in Nepal: following the policy process from analysis to action. In: Arusha Conference, "New Frontiers of Social Policy" World Bank ESSD Network, Arusha, December 12-15, 2005; Tanzania. Available from: http://www.k4health. $\mathrm{org} / \mathrm{sites} /$ default/files/Gender, $\% 20$ caste $\% 20$ and $\% 20$ ethnic $\% 20$ exclusion\%20in\%20Nepal.pdf. Accessed August 15, 2013.

11. Pandey JP, Dhakal MR, Karki S, Poudel P, Pradhan MS. Maternal and Child Health in Nepal: the effects of caste, ethnicity, and regional identity. Further analysis of the 2011 Nepal Demographic and Health Survey. Calverton, MD, USA: Nepal Ministry of Health and Population, New ERA, and ICF International; 2013. Available from: https://www. dhsprogram.com/pubs/pdf/FA73/FA73.pdf. Accessed July 17, 2014.

12. Charisse L, Mandimika WM, Alexandra M, et al. Knowledge of pelvic floor disorders in a population of community-dwelling women. $\mathrm{Am} J$ Obstet Gynecol. 2014;210(2):165. e1-e9.

13. Goman HM, Fetohy EM, Nosseir SA, Kholeif AE. Perception of genital prolapse: a hospital-based study in Alexandria (Part II). J Egypt Public Health Assoc. 2001;76(5-6):337-356.

14. Kulkarni R, Chauhan S. Socio-cultural aspects of reproductive morbidities among rural women in a district of Maharatra, India. J Fam Welf. 2009;55(2):26-33.

15. National Health Education Information Communication Centre. National Health Communication Policy, 2012. Available from: http://www.nheicc.gov.np/file/pdf/pdf8/16tHf9National\%20Health\% 20Communication\%20Policy_2012-Eng.pdf. Accessed August 20, 2013.

16. National Health Education Information Communication Centre (NHEICC). National Communication Strategy for Maternal, Newborn and Child Health. 2011. Available from: http://www.nheicc.gov.np/file/pdf/ pdf8/z2QkvyNational\%20Communication $\% 20$ Strategy $\% 20$ on $\% 20$ MNCH\%202012-2016.pdf. Accessed August 22, 2013.

17. Division of Family Health and Support for safe motherhood Nepal. Reaching consensus minimum package of MHN services: increasing access to essential care for mothers, newborns and children in Nepal. Ministry of Health and Population and SSMP, Kathmandu; 2005.

18. Afsar HA, Mahamood MA, Barney N, et al. Community knowledge, attitude and practices regarding sexually transmitted infections in a rural district of Pakistan. J Pak Med Assoc. 2006;56(1 Suppl 1):S50-S54.

19. Pradhan S. A Study of Uterine Prolapse Prevalence and its Causes in Siraha and Saptari Districts, Nepal. Kathmandu: Center for AgroEcology and Development; 2007.

20. Westoff CF, Bankole A. Mass Media and Reproductive Behavior in Pakistan, India, and Bangladesh. Analytical report no 10. Calverton, MD: Macro International Inc.; 1999. Available from: http://dhsprogram. com/pubs/pdf/AR10/AR10.pdf. Accessed July 17, 2014.

21. Acharya S, Shrestha N, Silwal PR, et al. A study on equity in health in Nepal. Kathmandu: Centre for Health Policy Research and Dialogue; 2008.

22. Vinitha CT, Singh S, Rajendran AK. Level of reproductive health awareness and factors affecting in a rural community of South India. Health Popul Perspect Issues. 2007;30(1):24-33.

23. Amnesty International UK. Nepal: Unnecessary Burden: Gender Discrimination and Uterine Prolapse in Nepal. ASA 31/001/2014. London: Amnesty international Ltd, Peter Benenson House; 2014. Available from: http://www.amnesty.org/en/library/info/ ASA31/001/2014/en. Accessed July 17, 2014. 
International Journal of Women's Health

Dovepress

\section{Publish your work in this journal}

The International Journal of Women's Health is an international, peerreviewed open-access journal publishing original research, reports, editorials, reviews and commentaries on all aspects of women's healthcare including gynecology, obstetrics, and breast cancer. The manuscript management system is completely online and includes Visit http://www.dovepress.com/testimonials.php to read real quotes from published authors.

Submit your manuscript here: http://www.dovepress.com/international-journal-of-womens-health-journal 